\title{
Synthesis and Characterization of $\mathrm{LuBa}_{2} \mathrm{Cu}_{3} \mathrm{O}_{z}$ Superconductors by Using of a Polymeric Precursor
}

\author{
Man Seok LEE - Ho Keun LEE* \\ Department of Physics, Kangwon National University, Chuncheon 200-701, Korea \\ Sang-II SEOK \\ Korea Research Institute of Chemical Technology, Daejeon 305-343, Korea \\ (Received 31 July 2013 : revised 6 August 2013 : accepted 10 October 2013)
}

\begin{abstract}
The Pechini polymeric precursor method was successfully used to synthesize polycrystalline $\mathrm{LuBa}_{2} \mathrm{Cu}_{3} \mathrm{O}_{z}$ (Lu-123) superconducting compounds. The results of X-ray diffraction (XRD), Scanning electron microscopy (SEM) and resistivity measurements showed that the Lu-123 phase was formed when heated at temperatures between $860{ }^{\circ} \mathrm{C}$ and $880{ }^{\circ} \mathrm{C}$ under a $9 \% \mathrm{O}_{2}-91 \% \mathrm{~N}_{2}$ atmosphere after pyrolysis of the precursor at $350{ }^{\circ} \mathrm{C}$ for $5 \mathrm{~h}$ in air and $600{ }^{\circ} \mathrm{C}$ for $3 \mathrm{~h}$ in $\mathrm{O}_{2}$. The polycrystalline samples sintered at $880^{\circ} \mathrm{C}$ under a low oxygen partial pressure revealed a single phase and showed superconductivity comparable to that of the sample prepared by using the solid state reaction method. Compared to the phase formation temperature of the sample prepared by the solid state reaction method, that of Lu-123 was found to be lower, possibly due to the fine particle size after the pyrolysis.
\end{abstract}

\section{Polymeric precursor를 이용한 $\mathrm{LuBa}_{2} \mathrm{Cu}_{3} \mathrm{O}_{z}$ 초전도체의 합성 및 특성 연구}

\author{
이만석 · 이호근* \\ 강원대학교 물리학과, 춘천 200-701 \\ 석상일 \\ 한국화학연구원, 대전 305-343
}

(2013년 7월 31일 받음, 2013년 8월 6일 수정본 받음, 2013년 10월 10일 게재 확정)

\begin{abstract}
Pechini polymeric precursor 법으로 다결정 $\mathrm{LuBa}_{2} \mathrm{Cu}_{3} \mathrm{O}_{z}(\mathrm{Lu}-123)$ 초전도체를 합성하는 연구를 수행했다. 이 방법으로 공기 중 $350{ }^{\circ} \mathrm{C}$ 에서 5 시간, 산소분위기로 $600{ }^{\circ} \mathrm{C}$ 에서 5 시간 열분해 한 후 $860 \sim 880^{\circ} \mathrm{C}$ 온도 영역에서 $9 \% \mathrm{O}_{2}-91 \% \mathrm{~N} 2$ 로 열처리하면 $\mathrm{Lu}-123$ 상이 형성됨을 $\mathrm{XRD}$ 로, 상기의 낮 은 산소분압으로 $880^{\circ} \mathrm{C}$ 에서 최종 소결한 결과 거의 단일상의 $\mathrm{Lu}-123$ 시편을 합성할 수 있음을 $\mathrm{SEM}$ 로 측정하여 알 수 있었다. 비저항 측정결과에서 임계온도는 고상반응법으로 합성한 결과와 거의 같 았다. 또한 고상반응법으로 합성한 경우에 비해 낮은 온도에서 $\mathrm{Lu}-123$ 상이 형성됨을 관측했으며, 이 는 Polymeric precursor 법으로 합성한 경우 열분해 후 분말크기가 상대적으로 작은 것에 기인하는 것으로 설명되었다.
\end{abstract}


PACS numbers: 74.72.-h, 74.72.Jf, 74.62.Bf, 74.25.Fy

Keywords: 합성, $\mathrm{LuBa}_{2} \mathrm{Cu}_{3} \mathrm{O}_{z}$, Polymeric precursor, 초전도

\section{I. 서 론}

1987년 약 $90 \mathrm{~K}$ 의 초전도 임계온도를 나타내는 $\mathrm{Y}$ $\mathrm{Ba}-\mathrm{Cu}-\mathrm{O}$ 계 초전도체가 $\mathrm{Wu}$ 등 [1] 에 의해 처음으로 발 견된 후 이 초전도체는 $\mathrm{YBa}_{2} \mathrm{Cu}_{3} \mathrm{O}_{7-z}$ 계의 구성을 갖는 것으로 밝혀졌으며, 이어 $\mathrm{Y}$ 대신 대부분의 희토류 원소 를 $\mathrm{Y}$ 대신 치환하더라도 약 $90 \mathrm{~K}$ 의 초전도체가 합성됨 이 보고 [2] 되었다. 그러나 희토류 원소 중 Ce (cesium), $\mathrm{Tb}$ (terbium) 및 $\mathrm{Lu}$ (lutetium) 의 경우는 123 상이 형 성되지 않는 것으로 알려져 왔다 [2-4]. 특히 $\mathrm{Lu}$ 의 경 우 $900{ }^{\circ} \mathrm{C} \sim 1000^{\circ} \mathrm{C}$ 의 온도영역에서 통상의 고상반응 법으로는 다결정 벌크Lu-123 상이 형성되지 않음이 잘 알려져 있다 [5]. 그런데 최근 Lee [6] 는 매우 좁은 열 처리 온도 및 산소 분압에서 고상반응법으로 단일상의 $\mathrm{Lu}-123$ 벌크 초전도체를 합성하는 방법을 처음으로 밝혔 다. 본 연구는 그의 연구에 기반하여 균질한 혼합이 가 능한 polymeric precursor 방법으로 벌크 Lu-123 초전도 체를 합성하고 그 특성을 고상반응법으로 합성한 시편 의 특성과 비교했다.

\section{II. 실험 방법}

시편은 고상반응법과 Polymeric precursor 방법으로 합성했다. 고상반응법에 의한 시편의 합성은 참고문헌 [6] 에 기술된 방법으로 수행되었으며, 합성 때 순도 $99.9 \%$ 이상의 $\mathrm{Lu}_{2} \mathrm{O}_{3}, \mathrm{BaCO}_{3}$ 및 $\mathrm{CuO}$ 분말이 이용되었 다. Polymeric Precursor 방법에 의한 시편의 합성은 이 방법으로 Y-123 초전도체를 합성한 경우 [7] 를 바탕으 로 여러 가지로 합성이 시도되었다.

본 연구의 방법에서는 먼저 $99.9 \%$ 순도를 가지는 $\mathrm{LuN}_{3} \mathrm{O}_{9}$ 분말과 $99.999 \%$ 순도인 $\mathrm{BaCO}_{3}, \mathrm{CuO}$ 의 분말 을 이용하고 양이온의 비가 $\mathrm{Lu}: \mathrm{Ba}: \mathrm{Cu}=1: 2: 3$ 이 되도록 정량화 한 후, 각 분말을 $60 \%$ 질산용액에 넣고 가열하여 용해한 뒤 혼합시키고 총 금속이온의 1.2 배의 몰비 만 큼 citric acid를 첨가하여 균일하게 혼합되어 있는 metal citrate 용액을 만들었다.

혼합용액은 rotary evaporator로 감압 증류하여 metal citric salts을 얻은 후 첨가한 citric acid $1 \mathrm{~g}$ 당 $2 \mathrm{ml}$ 의

*E-mail: hklee221@kangwon.ac.kr

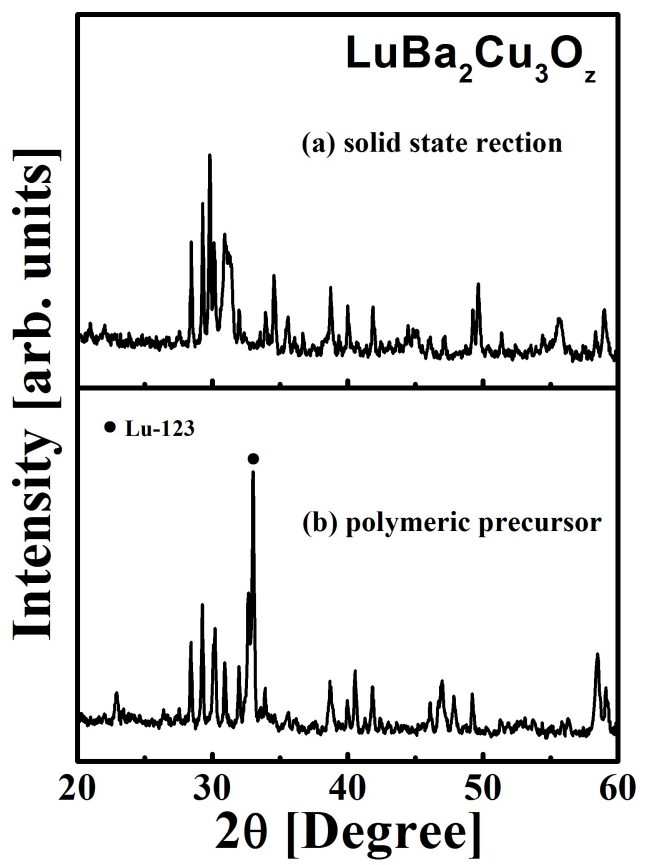

Fig. 1. XRD patterns calcined at $860^{\circ} \mathrm{C}$ for samples prepared by (a) solid state reaction method and (b) polymeric precursor method.

ethylene glycol를 넣어 혼합하고 약 $130{ }^{\circ} \mathrm{C}$ 에서 polymerization 반응에 의하여 고점도 겔형의 polymeric precusor를 얻었다. 이렇게 얻어진 precursor를 오븐에서 $350^{\circ} \mathrm{C}$ 로 5 시간 열분해 시킨 후 가볍게 분쇄하여 다시 $600{ }^{\circ} \mathrm{C}$ 로 $\mathrm{O}_{2}$ 가스 분위기에서 5 시간 열분해 하여 미세분 말을 얻었다. 고상반응법으로 시편을 합성할 때도 비교 를 위해 처음 혼합하여 분쇄된 분말을 $600^{\circ} \mathrm{C}$ 에서 같은 조건과 시간으로 열처리했다. 이후의 열처리는 최근 Lee [6] 에 의해 연구된 방법으로 기초로 하여 $860{ }^{\circ} \mathrm{C}$ 로 $9 \%$ $\mathrm{O}_{2}, 91 \% \mathrm{~N} 2$ 혼합가스 분위기에서 10 시간 하소하였고 동 일한 혼합가스 분위기로 두 번에 걸쳐 $870^{\circ} \mathrm{C}$ 에서 10 시 간, $880^{\circ} \mathrm{C}$ 에서 10 시간 소결하여 다결정 벌크 초전도체 를 합성하였다.

하소와 소결에 따른 X-선 회 절 (XRD; X-ray diffraction) 분석은 $\mathrm{Cu} \mathrm{K \alpha} \alpha$ 선을 이용한 $\mathrm{X}$-선 회절장치 (PANalytical X'pert-pro MPD)가 이용되었으며, 시편의 입도 및 미세조직은 고분해능 주사전자 현미경 (SEM; scanning electron microscope, Hitachi S-4800) 으로 조사되 었 다. 시편의 비저항 특성은 은풀을 이용하여 접착된 4 단 자 접점법으로 $10 \mathrm{~mA}$ 의 전류를 흘려 측정했다. 


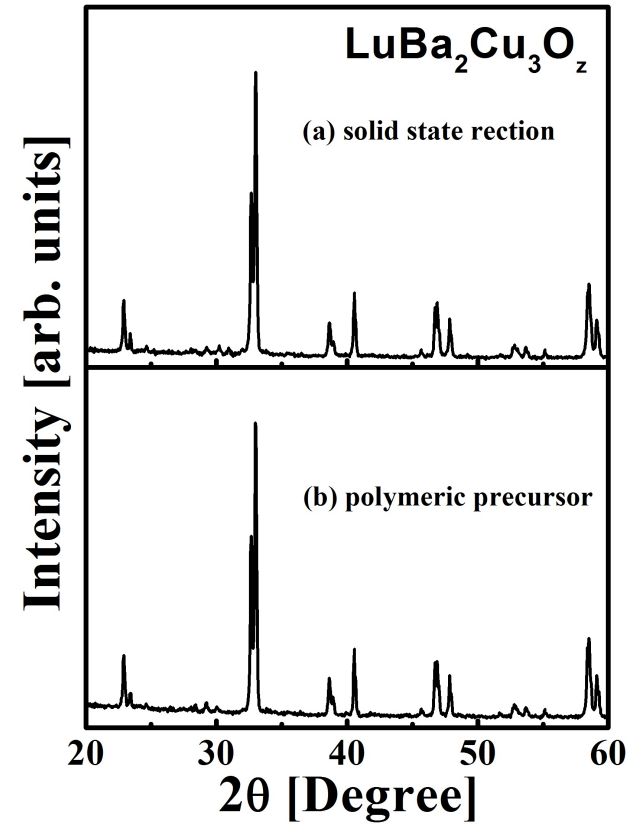

Fig. 2. (XRD patterns sintered at $880^{\circ} \mathrm{C}$ for samples prepared by (a) solid state reaction method and (b) polymeric precursor method.

\section{III. 실험 결과 및 토의}

Figure 1은 고상반응법과 polymeric precursor 법으 로 얻어진 분말을 $860^{\circ} \mathrm{C}$ 에서 하소한(calcined) 후 얻어 진 X-선 회절 패턴을 보여준다. 고상반응법으로 합성된 시편의 경우 아직 Lu-123 상이 형성되지 못하고 주로 $\mathrm{BaCuO}_{2}, \mathrm{Lu}_{2} \mathrm{BaCuO}_{5}$ 및 $\mathrm{CuO}$ 상이 관측되며 이는 Lee [6]가 관측한 결과와 일치한다. 이에 비해 polymeric precursor 방법으로 합성된 X-선 회절 패턴(b)은 $\mathrm{BaCuO}_{2}$, $\mathrm{Lu}_{2} \mathrm{BaCuO}_{5}$ 및 $\mathrm{CuO}$ 상 외 Fig. 1 에 표시된 바와 같이 Lu-123 상의 주 회절선이 관측된다. 이는 polymeric precursor 법으로 얻어진 분말의 경우 이 온도에서 Lu-123상 이 형성됨을 의미하며, 따라서 polymeric precursor 법으 로 분말을 준비하면 고상반응법으로 준비한 분말에 비 해 보다 낮은 온도에서 Lu-123상을 형성시킬 수 있음을 지시하는 것으로 볼 수 있다. Fig. 2는 실험 방법에서 언 급한 절차에 따라 최종적으로 $880^{\circ} \mathrm{C}$ 에서 소결한 (sintered) 후 얻어진 X-선 회절 패턴을 보여주며, 두 경우 모두 거의 단일상 시편이 합성됨을 보여준다. 123 계 구 리산화물의 일반적인 하소 및 소결 과정에서는 참고문 헌 [5]에 언급된 바와 같이 주로 $900{ }^{\circ} \mathrm{C} \sim 950{ }^{\circ} \mathrm{C}$ 온도 영 역에서 하소하며, 소결은 주로 $900{ }^{\circ} \mathrm{C} \sim 1000^{\circ} \mathrm{C}$ 온도 영 역에서 행해진다. 이 때 열처리는 공기 또는 산소 분위기 에서 행해지고 있다. 이에 비해 본 연구의 Lu-123 초전 도체의 합성 과정에서는 약 $10 \%$ 의 낮은 산소 분압 분위
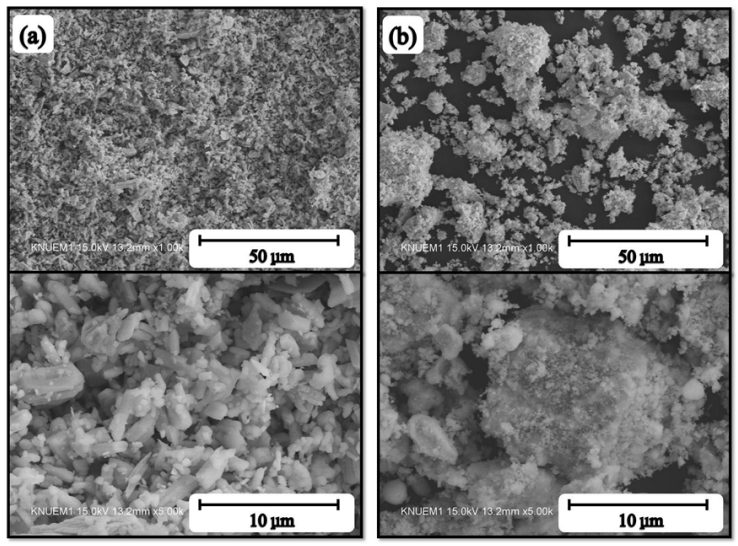

Fig. 3. SEM photographs after pyrolysis at $600^{\circ} \mathrm{C}$ for samples prepared by (a) solid state reaction method and (b) polymeric precursor method.

기와 $860^{\circ} \mathrm{C} \sim 900^{\circ} \mathrm{C}$ 좁은 온도 영역의 열처리가 중요 하다는 실험결과 [6]에 근거해 하소 및 소결 실험이 수행 되었다. 특히 $\mathrm{Lu}-123$ 상이 형성되는 과정에서 $\mathrm{BaCuO}_{2}$, $\mathrm{Lu} 2 \mathrm{BaCuO} 5$ 및 $\mathrm{CuO}$ 상이 줄어들었다고 볼 수 있으므로 이들 상이 Lu-123으로 변환됨을 지시한다. 따라서 열처 리에 따른 Lu-123 상의 형성과정은 수식적으로 다음과 같은 공식(1)로 표현할 수 있다.

$$
\begin{array}{r}
0.5 \mathrm{Lu}_{2} \mathrm{BaCuO}_{5}+1.5 \mathrm{BaCuO}_{2}+\mathrm{CuO}+ \\
(0.25-x / 2) \mathrm{O}_{2} \rightarrow \mathrm{LuBa}_{2} \mathrm{Cu}_{3} \mathrm{O}_{7-x}
\end{array}
$$

Figure 1에 나타난 바와 같이 $860^{\circ} \mathrm{C}$ 열처리에서 상형 성 특성의 변화가 있다는 것은 두 방법으로 준비된 분 말에 어떤 차이가 있음을 시사하며, 이를 조사하기 위해 두 방법에서 $600{ }^{\circ} \mathrm{C}$ 로 같은 조건으로 열처리한 후 얻어 진 분말을 $\mathrm{SEM}$ 으로 관찰한 결과가 Fig. 3 에 나타나 있 다. 고상반응법으로 합성한 분말(a)는 입자의 크기가 약 $0.5 \mu \mathrm{m} \sim 4 \mu \mathrm{m}$ 이며 입자가 고르게 분포하는 것을 볼 수 있고 polymeric precursor 법으로 합성한 분말(b)는 입자 의 크기가 약 $0.1 \mu \mathrm{m} \sim 1 \mu \mathrm{m}$ 로 미세하며 입자들이 서로 뭉쳐져서 덩어리 형태로 분포하는 것을 볼 수 있다. 그 러므로 polymeric precursor 법을 이용하면 미세한 분말 을 합성할 수 있으며 이로 인해 상대적으로 낮은 온도의 열처리로도 Lu-123상이 형성되는 것으로 볼 수 있다. 본 연구의 결과는 또한 polymeric precursor 법이 미세분말 의 합성이 가능하여 고상반응법에 비해 후막의 제작에 도 유리할 것으로 사료된다. Fig. 4 는 $880^{\circ} \mathrm{C}$ 로 최종 소 결한 시편의 $\mathrm{SEM}$ 관측결과이다.

Figure 4(a)에 보여준 고상반응법으로 합성한 시편 보 다 Fig. 4(b)에 보여준 polymeric precursor 법으로 합성 한 시편의 미세구조가 보다 치밀한 것을 알 수 있다. 이 

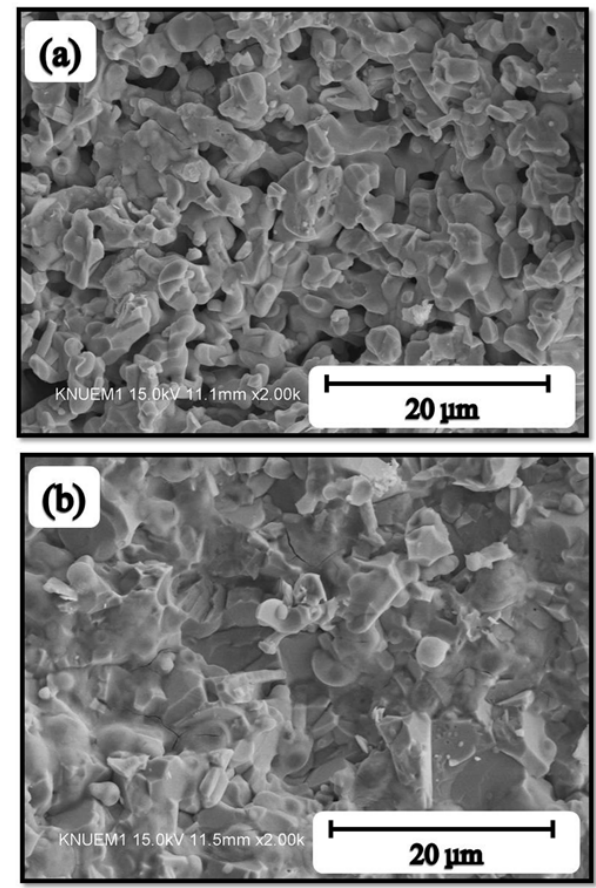

Fig. 4. SEM photographs for Lu-123 bulk samples prepared by (a) solid state reaction method and (b) polymeric precursor method.

결과는 polymeric precursor 법으로 시편을 합성하면 고 상반응법에 비해 시편의 임 계밀도를 크게 향상시킬 가능 성이 높음을 지시한다. 이들 최종 소결된 시편의 비저항 측정 결과가 Fig. 5 에 나타나 있다. 비저항의 크기는 두 시편이 거의 유사함을 보여주며, 저항이 0이되는 온도는 고상반응법의 경우 $88 \mathrm{~K}$ 그리고 polymeric precursor 법 의 경우 $86 \mathrm{~K}$ 로 거의 유사함을 보여준다.

\section{IV. 결 론}

Pechini polymeric precursor 법으로 다결정 $\mathrm{LuBa}_{2} \mathrm{Cu}_{3} \mathrm{O}_{z} \quad(\mathrm{Lu}-123)$ 초전도체를 합성하는 연구 를 수행했으며, 그 결과 $860 \sim 880^{\circ} \mathrm{C}$ 도 영역에서 $9 \%$ $\mathrm{O}_{2}-91 \% \mathrm{~N}_{2}$ 로 열처리하면 단일상의 벌크 $\mathrm{Lu}-123$ 초 전도체를 합성할 수 있음을 보였다. 또한 polymeric precursor 법으로 분말 시편을 합성하면 고상반응법에 비해 미세한 분말합성이 가능하고, 이로 인해 상대적으 로 낮은 온도에서 Lu-123상을 형성시킬 수 있을 뿐 아니 라 보다 치밀한 소결체를 합성할 수 있음을 알 수 있었 다. Polymeric precursor 방법으로 합성된 시편의 임계 온도는 고상반응법으로 합성한 시편과 거의 유사했다. 따라서 Polymeric precursor 방법을 이용하면 높은 밀도 의 $\mathrm{Lu}-123$ 초전도체 물질의 합성이 가능하여 임계밀도 의 향상에 응용할 수 있을 것으로 예상된다.

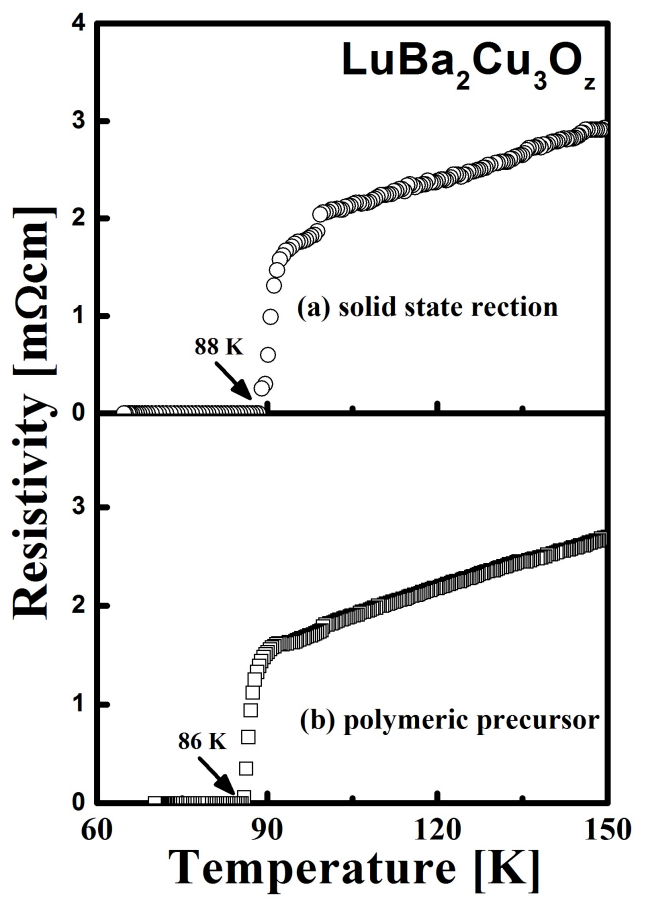

Fig. 5. Resistivity vs. temperature data for $\mathrm{LuBa}_{2} \mathrm{Cu}_{3} \mathrm{O}_{z}$ samples prepared by (a) solid state reaction method and (b) polymeric precursor method.

\section{감사의 글}

본 연구의 $\mathrm{XRD}$ 측정은 강원대학교 공동실험실습관 의 장비로 측정되었다.

\section{REFERENCES}

[1] M. K. Wu, J. R. Ashburn, C. J. Torng, P. H. Hor and R. L. Meng et al., Phys. Rev. Lett. 58, 908 (1987).

[2] P. H. Hor, R. L. Meng, Y. Q. Wang, L. Gao and Z. J. Huang et al., Phys. Rev. Lett. 58, 1891 (1987).

[3] J. M. Tarascon, W. R. McKinnon, L. H. Greene, G. W. Hall and E. M. Vogel, Phys. Rev. B 36, 226 (1987).

[4] A. R. Moodenbaugh, M. Suenaga, T. Asano, R. N. Shelton and H. C. Ku et al., Phys. Rev. Lett. 58, 1885 (1987).

[5] E. Hodorowicz, S. A. Hodorowicz and H. A. Eick, J. Alloys Compd. 181, 442 (1992).

[6] H. K. Lee, J. Supercond. Novel Magn. 25, 2519 (2012).

[7] H. K. Lee, D. Kim and S. I. Suck, J. Appl. Phys. 65, 2563 (1989). 